\begin{tabular}{|l|l|l|l|l|l|l|}
\hline InterteXto & Uberaba & UFTM & $\begin{array}{l}\text { v. 1 } \\
\text { n. } 2\end{array}$ & p. 82-95 & 2008 - jul. / dez. & ISSN 1981-0601 \\
\hline
\end{tabular}

\title{
RUAS ALAGADAS E BECOS ESCUROS: PERCURSOS PELA CIDADE NO CONTO BRASILEIRO CONTEMPORÂNEO
}

\author{
FLOODING STREETS AND DARK ALLEYS: CROSSING THE CITY IN THE \\ CONTEMPORARY BRAZILIAN SHORT STORY
}

Antônio João Galvão de Souza ${ }^{1}$

\begin{abstract}
Resumo
O conto é o gênero que melhor acompanhou as transformações do urbano no século XX devido a sua brevidade, densidade e concisão de enredo na representação das cidades, tanto geograficamente quanto de seus territórios sociais. Assim, tendo como premissa a representação dos aspectos materiais e imateriais da cidade ser construída a partir de imaginários que pluralizam o real concreto, tal como lemos em Chartier (1990); entendendo pelo espaço a percepção e a compreensão dos modos como o mundo nos atinge, segundo Lotman (1978); e analisando o andar noturno de personagens pela cidade através de suas trajetórias múltiplas, como sugere Certeau (1994), debruçamo-nos sobre as práticas e usos metafóricos lidos nos contos "Frio", de João Antônio e "Além do ponto", de Caio Fernando Abreu. Vemos, nas narrativas aqui discutidas, discursos privilegiados para captar representações singulares e também descobrimos sentidos outros nos espaços escuros da cidade brasileira contemporânea.

Palavras-chave: representação; conto brasileiro contemporâneo; poética do espaço.
\end{abstract}

\section{Abstract}

The short story is the genre which best followed the $20^{\text {th }}$ century urban transformations due to its brief, dense and concise plot in the representations of cities, both geographically and also its social territories. Then, considering that the city's material and immaterial aspects are represented as from imaginaries which pluralize the concrete real, as we read in Chartier (1990); understanding from the space the perception and comprehension of the many ways the world reaches us, according to Lotman (1978); and analyzing the characters' night walk in the city as from their multiple directions, as suggested by Certeau (1994), we explore the metaphorical practices and uses read in João Antônio's "Frio"and Caio Fernando Abreu's "Além do ponto". In the narratives here discussed we see privileged discourses which capture singular representations and we also find out other meanings in the dark spaces of the contemporary Brazilian city.

Key-words: representation; contemporary brazilian short story; space poetics.

\footnotetext{
1. Mestrando em Estudos Literários pela Universidade Federal de Goiás. Pesquisador do grupo "Investigações em narrativa contemporânea de língua portuguesa" (CNPq). antoniojoao1@gmail.com
} 


\begin{tabular}{|l|l|l|l|l|l|l|}
\hline InterteXto & Uberaba & UFTM & $\begin{array}{l}\text { v. 1 } \\
\text { n. } 2\end{array}$ & p. 82-95 & 2008 - jul. / dez. & ISSN 1981-0601 \\
\hline
\end{tabular}

Entre as inúmeras formas de abordar a história cultural do urbano há aquela proporcionada pela literatura, posto que ela também traz representações do espaço e do real passado. O olhar literário, ao captar os discursos e as imagens dispostas sobre esse urbano, pluraliza lugares e os ressignifica, ampliando os diferentes imaginários construídos sobre as cidades brasileiras no século XX. Esses imaginários podem recriar o real, pois operam como idéias e imagens coletivas construídas a partir de uma intrincada relação entre estimulações sensoriais exteriores e sedimentações culturais. Em outras palavras, o que concebemos como realidade é, na verdade, algo como uma "realidade simulada". Essa constatação permite-nos compreender as representações do mundo como uma outra manifestação da realidade que nos atinge todos os dias. Em muitos casos, esse real "imaginado" tem maior impacto sobre os percursos das relações sociais do que o real "concreto", como observa Roger Chartier (1990).

Concreta ou imaginada, colocamo-nos diante da cidade na tentativa de abordar certas representações do real fornecidas pela literatura a ela. Contraditória e plural, a cidade contemporânea é o espaço para o qual convergem e de onde emergem múltiplos olhares, discursos justapostos e entrecruzados, jamais hierarquizados. Assim, o urbano manifesta-se metaforicamente nos diferentes discursos que buscam representar a cidade para dela depreender cadeias de significados. É dessa maneira que Sandra Jatahy Pesavento (2002) nota como tais usos metafóricos, oferecidos pela narrativa literária, moldam os discursos sobre o urbano: outras palavras são acionadas, a mesma cidade é imaginada de inúmeros outros modos, as representações do cotidiano são constantemente deslocadas.

Dentro dessa perspectiva, a literatura insinua-se como discurso ímpar para acessar essas representações, visualizar tais imaginários e perscrutar sentidos, pois o olhar literário, ao flagrar a cidade, debruça-se sobre suas infinitas ruas, seus ínfimos transeuntes, agora personagens, e as 


\begin{tabular}{|l|l|l|l|l|l|l|}
\hline InterteXto & Uberaba & UFTM & $\begin{array}{l}\text { v. 1 } \\
\text { n. } 2\end{array}$ & p. 82-95 & 2008 - jul. / dez. & ISSN 1981-0601 \\
\hline
\end{tabular}

sociabilidades por eles travadas. Apresentando as alterações do espaço urbano e capturando as sensibilidades do passado, a literatura produz diferentes representações da cidade. Elas constituem possibilidades de existência de enredos, personagens e tramas que, embora imaginárias, podem ser construídas a partir de experiências concretas, ou não, no espaço da cidade.

Cidade chama, cidade sonho, cidade ambígua, tal como a lemos em "As cidades invisíveis" (CALVINO, 1990), os imaginários que acerca dela são elaborados sustentam-se sobre os espaços dessa cidade. É a partir da linguagem das relações espaciais esboçadas nos territórios urbanos, tais como ir a algum lugar, voltar de outro, atravessar ruas e avenidas, que a literatura abrange o real, já que entendemos, percebemos e concebemos o mundo pelo espaço, de tal modo que a orientação pelo espaço tenta prover coerência à maneira como o mundo nos atinge. Dessa forma, sugere luri Lotman (1978):

Os modelos sociais, religiosos, políticos e morais do mundo, com a ajuda dos quais o homem, nas diferentes etapas de sua história, confere sentido à vida que o rodeia, encontram-se invariavelmente providos de características espaciais, quer sob a forma de oposições, quer sob a forma de hierarquias políticosociais (LOTMAN, 1978, p. 361).

Isto é, as relações sociais humanas, engendradas nos múltiplos espaços da cidade, estão marcadas por distinções tecidas no urbano: há sempre um perto e um longe; lugares escuros e outros bruscamente iluminados; ruas tornadas escusas pelas práticas nelas realizadas e que se opõem ao discurso dos chamados "ambientes familiares". A linguagem do texto literário absorve essas diferentes posições espaciais quando associa certas palavras, quase sempre metafóricas, a determinados lugares. Aliás, é precisamente essa manipulação pela metáfora, uma outra maneira de dizer a mesma cidade, que desarticula os modelos prontos e previsíveis construídos sobre os espaços e os transporta a outros níveis de imaginação. É o autor do texto quem rompe essas fronteiras discursivas e cria outras associações por contraste entre planos 


\begin{tabular}{|l|l|l|l|l|l|l|}
\hline InterteXto & Uberaba & UFTM & $\begin{array}{l}\text { v. 1 } \\
\text { n. } 2\end{array}$ & p. 82-95 & 2008 - jul. / dez. & ISSN 1981-0601 \\
\hline
\end{tabular}

previamente concebidos e por negação do verossímil, por exemplo. Ainda pensando com Lotman, diríamos que o espaço da cidade na literatura brasileira contemporânea é, geralmente, polifônico, complexa teia na qual transitam personagens instáveis e de cujas práticas podemos apreender apenas indícios.

Aliás, a literatura brasileira dos últimos trinta anos é predominantemente urbana, conforme indica Flora Süssekind (2005). A partir de uma abordagem de vínculos entre sociedade e literatura, via fecunda na qual Antonio Candido é expoente na América Latina, a autora percebe a concentração da população brasileira nas cidades nos últimos anos. Mas se por um lado tal circunstância pode direcionar a reconfigurações artísticas e literárias das tensões entre o regional e o urbano, por outro não implica, necessariamente, em uma relação direta e unívoca das mediações entre espaço urbano e forma artística. Afinal, segundo Süssekind,

[...] as duplicações e representações do real não têm significado, necessariamente, na complexificação dos recursos formais, da pratica literária e da experiência histórica recente. Muitas vezes essa complexificação resulta não exatamente de representações explícitas ou documentais do urbano, mas da produção de espaços não-representacionais e de zonas liminares, ambivalentes, transicionais, da subjetividade (SÜSSEKIND, 2005, p. 61).

Desse modo, a produção literária brasileira recente não é apenas reflexo de um maior contingente populacional em grandes cidades. Literatura é recriação do real, deslocamento constante de cadeias de significados, amplo exercício de imaginação. É claro que sobre a narrativa literária incidem a cidade e todos os seus diferentes mitos, lendas, legendas, códigos e sinais, mas de uma forma ambivalente e sinuosa, produzindo espaços outros, para além daqueles oferecidos pelo real tido como concreto.

Assim, chegamos à proposta de repensar o espaço das cidades na literatura por meio de uma "metaforização do social". Alan Mons (1992, apud PESAVENTO, 2002) percebe dois tipos de metáforas dispostas sobre o urbano: as metáforas visíveis, manifestadas, por exemplo, pela agressividade 


\begin{tabular}{|l|l|l|l|l|l|l|}
\hline InterteXto & Uberaba & UFTM & $\begin{array}{l}\text { v. 1 } \\
\text { n. } 2\end{array}$ & p. 82-95 & 2008 - jul. / dez. & ISSN 1981-0601 \\
\hline
\end{tabular}

publicitária na cidade, as pichações em muros e estações de ônibus e metrôs, o traçado de ruas, avenidas, praças, os monumentos históricos e os prédios do centro da cidade, as imagens urbanas visuais apreendidas por fotografias, diferentes estilos arquitetônicos, pinturas e esculturas; e as práticas metafóricas, sejam elas públicas ou privadas, que se insinuam e se inscrevem difusamente nos espaços da cidade. Enquanto as metáforas visíveis, podendo até alterar os sentidos literais de uma cidade, são quase sempre explícitas, as práticas metafóricas são mínimas e dispersas. Agem sempre por implícitos, surgem e desaparecem esporadicamente nos becos, ruas e avenidas.

Tensionada ao limite da representação, essa prática metafórica conduznos a exercícios de fuga de um olhar totalizante sobre as cidades, posto que ele não daria conta de abranger o real e suas representações. Há, assim, toda uma estranheza do cotidiano que não emerge facilmente ou que não se destaca sobre o visível, mas cuja visualização pode ser vislumbrada pelo texto literário. É dessa forma que queremos apreender representações do espaço urbano, através de percursos pela cidade, nos contos "Frio", de João Antônio e "Além do ponto", de Caio Fernando Abreu, em uma perspectiva na qual as cidades revelam-se como espaços que problematizam o imaginário.

Nota Michel de Certeau (1994) que uma das formas de se tentar perceber a cidade é caminhar por ela. Sendo um simulacro visual ou ainda um quadro cuja possibilidade de existência são também os esquecimentos sobre o urbano e o desconhecimento das práticas nele realizadas, a cidade é tomada por pedestres cujo andar escreve textos, percorre lugares invisíveis e que fogem às legibilidades. Como as trajetórias são continuamente fragmentadas e os espaços alterados, o conhecimento dos percursos pela cidade é mínimo. Disso decorre que sua representação é sempre outra. Desse modo, Certeau sugere o acompanhar desses passos, procedimentos multiformes e plurais, os quais levariam a uma teoria do espaço vivido ao salientar práticas estranhas ao espaço geográfico ou geométrico das cidades, pois: 


\begin{tabular}{|l|l|l|l|l|l|l|}
\hline InterteXto & Uberaba & UFTM & $\begin{array}{l}\text { v. 1 } \\
\text { n. } 2\end{array}$ & p. 82-95 & 2008 - jul. / dez. & ISSN 1981-0601 \\
\hline
\end{tabular}

Essas práticas do espaço remetem a uma forma específica de operações (maneiras de fazer), a uma outra espacialidade (uma experiência poética e mítica do espaço) e a uma mobilidade opaca e cega da cidade habitada. Uma cidade metafórica insinua-se assim no texto claro da cidade visível e planejada. Analisar as práticas singulares e plurais; seguir as minúcias desses procedimentos, caminhadas, percursos pela cidade que se reforçam em proliferações ilegitimadas, desenvolvidos e insinuados nos interstícios da vigilância e do controle, combinados segundo táticas ilegíveis (CERTEAU, 1994, p. 172).

Tentar abranger a cidade pelo andar de personagens no texto literário. Mas o que faz andar as personagens dos contos aqui analisados? Ou ainda, por que um direcionamento de leitura pelo equívoco e pela ambigüidade dos passos? Porque andar é um inumerável de singularidades. Porque "Caminhar é ter falta de lugar" (Certeau, 1994, p. 183), é errância, multiplicada e dispersa pela cidade, o que faz do urbano uma imensa experiência social de privação do lugar, esfacelada em deportações inumeráveis e mínimas dos deslocamentos e das caminhadas. No entanto, e essa observação faz toda a diferença, o cruzamento dessa teia de êxodos com as relações sociais representadas em literatura, cria um tecido urbano que pode ser legível pois esses passos escrevem textos e instauram discursos na cidade:

Os passos tecem lugares, moldam espaços, espacializam a cidade, transformam-se em mapas urbanos, trajetórias, rotas, desviam os sentidos literais dos percursos, alteram rotas previstas pelo sistema urbanístico, deslocam sentidos para equívocos: instauram uma retórica, a fala dos passos perdidos, já que fazem a cidade desaparecer em certas regiões, exageram-na em outras, distorcem-na, fragmentam e alteram sua ordem no entanto instável (CERTEAU, 1994, p. 176).

Assim, interessa-nos uma apreensão metafórica da cidade por meios de discursos criados através de experiências poéticas do espaço. Experiências que pluralizem o urbano e dêem-lhe significados outros. Desse modo, surgem dois funcionamentos distintos, entretanto relacionados, das relações entre práticas de espaço e seus possíveis significados: o crível e o memorável. 


\begin{tabular}{|l|l|l|l|l|l|l|}
\hline InterteXto & Uberaba & UFTM & $\begin{array}{l}\text { v. 1 } \\
\text { n. } 2\end{array}$ & p. 82-95 & 2008 - jul. / dez. & ISSN 1981-0601 \\
\hline
\end{tabular}

Certeau (1994) ressalta que o discurso do crível autoriza e possibilita apropriações espaciais enquanto o memorável carrega práticas repetidas ou ainda recordadas em um dado espaço, resíduos de uma memória silenciosa e fechada. Esses dois funcionamentos simbólicos esboçam discursos sobre a cidade de tal forma que a sistematicidade urbana pode ser totalmente alterada. Eles tornam crível o lugar porque o nomeiam, isto é, vestem-no com uma palavra. Evocam memórias que ainda perambulam, escondidas nos gestos e nos corpos que caminham pela cidade.

\section{Os becos escuros do centro de São Paulo: o crível}

As personagens de João Antônio são conhecidas pela incursão nas práticas silenciosas do submundo paulistano à noite. Dispersos em bares sujos do centro, entre cigarros e apostas nas mesas de sinuca ou ainda nos distantes e perigosos bairros da periferia de São Paulo, seus malandros empreendem lutas diárias pela sobrevivência. No conto "Frio", publicado em Malagueta, Perus e Bacanaço pela primeira vez em 1963, lemos a travessia de ruas e avenidas da capital paulista por um menino engraxate de dez anos, durante a madrugada. Ele dormia quando Paraná, um amigo mais velho com quem mora, pede-lhe que leve um embrulho até o bairro Perdizes. São duas horas da manhã e, a despeito do frio, o menino atende o amigo e atravessa a cidade a pé.

Quase uma hora andando, ele se apressa pois é preciso chegar rápido. Da cidade à noite emergem perigosos carros velozes, guardas hostis, mulheres trabalhando nas ruas. Paraná advertiu-Ihe para não ficar olhando as coisas. No entanto, o menino tudo olha, principalmente as luzes das avenidas do centro. Então, a cidade surge por seus diversos nomes e referenciais: ele deve ir até um ferro-velho em Perdizes, naquela grande avenida, próxima a uma igreja, descer três quarteirões. Atravessar a Rua Duque de Caxias, a Avenida São João, o Largo Padre Péricles, a Avenida Água Branca. Enquanto cruza longos 


\begin{tabular}{|l|l|l|l|l|l|l|}
\hline InterteXto & Uberaba & UFTM & $\begin{array}{l}\text { v. 1 } \\
\text { n. } 2\end{array}$ & p. 82-95 & 2008 - jul. / dez. & ISSN 1981-0601 \\
\hline
\end{tabular}

trechos de São Paulo a pé, ele pensa na casa de Nora, amante de Paraná, na Barra Funda, no outro lado da cidade. E projeta também a parte final da Rua João Teodoro, na Vila Pompéia, onde engraxa sapatos durante o dia.

Para esse menino, a cidade são nomes. Nomes de ruas, avenidas, praças, espaços públicos tornados privados pela injunção de um nome. $O$ discurso do crível, ao nomear a cidade, torna seus espaços habitáveis. Avenida São João, Vila Pompéia e Barra Funda povoam o imaginário do menino de dez anos em decorrência de seus nomes, concedidos pela administração da cidade. Essa administração impõe normas, anuncia projetos e tenta realizar atos controláveis nesses espaços urbanos, isto é, eles são concebidos para a concretização de práticas supervisionáveis: o trânsito de carros e pedestres pelas vias limpas e iluminadas; a manutenção da segurança de ruas, casas e prédios pela força policial do Estado; o uso adequado dos espaços públicos segundo normas unidirecionais. Em outras palavras, "Satura de significados alguns lugares e os reduz a eles, a ponto de os tornar irrespiráveis" (CERTEAU, 1994, p. 187).

Entretanto, o percurso a pé dessa personagem de João Antônio, pela madrugada fria de São Paulo, é também uma outra autoridade que se insinua e espacializa certos segmentos da cidade. Instaura outros usos e desnuda outras práticas além daquelas previstas e concebidas pelo discurso crível e habitável da administração. O crível, isto é, a São Paulo primeira, oferecida por uma percepção inicial, a funcionalista, é então desarticulado em "Frio" por práticas mínimas e singulares daquele pedestre. Outras simbologias e pluralidades são dispostas naqueles espaços repletos de nomes: o do percurso pela cidade a pé e à noite. 


\begin{tabular}{|l|l|l|l|l|l|l|}
\hline InterteXto & Uberaba & UFTM & $\begin{array}{l}\text { v. 1 } \\
\text { n. } 2\end{array}$ & p. 82-95 & 2008 - jul. / dez. & ISSN 1981-0601 \\
\hline
\end{tabular}

Já seriam duas e pouco. Frio. Canseira. As casas enormes esguelhavam a Avenida muito larga. Pela Avenida Água Branca o menino preto ia encolhido. Só dez anos. No tênis furado entrando umidade. Os autos eram poucos, mas corriam, corriam aproveitando a descida longa. Tão firmes que pareciam homens. O menino ia só" (JOÃO ANTÔNIO, 2004, p. 103).

A leitura dessa travessia de São Paulo, por seus becos e ruas escuras, contradiz o discurso do crível pelo surgimento de legendas e superstições, práticas outras realizadas nas minúcias do espaço urbano, em seus becos escuros, às quais o texto literário permite-nos acesso. Inventam-se outros espaços de habitabilidade. Isto é, o conto de João Antônio, ao negar o crível, permite-nos entrever diferentes camadas semânticas, ouvir ricos silêncios e histórias sem palavras:

$\mathrm{Na}$ estação de Sorocabana perguntou as horas a uma mulher. Sempre ficavam mulheres vagabundeando por ali, à noite. Pelo jardim, pelos escuros da Avenida Cleveland. Ela Ihe deu, ele seguiu. Os bondes passavam. (...) Evitava os olhares dos guardas. A Avenida teria muitos, era preciso, quem sabe, desguiar. Enfiar-se, talvez, pelas ruas transversais. Mas temeu perder-se nas tantas travessas e não encontrar a igreja das Perdizes. la tremelicando, mas ia (JOÃO ANTÔNIO, 2004, p. 95 e 102).

Há uma estação ali, apenas que utilizada para outros fins, por outros praticantes nesse período da noite na enorme Babel paulistana. A Avenida Cleveland e o jardim, se durante o dia iluminados, tomados por pessoas apressadas, indo para ou voltando de seus trabalhos, ocupadas com obrigações tipicamente matinais como comprar jornais e pães e pagar contas no banco, à noite revelam-se, no texto de João Antônio, espaços de afazeres outros, os quais são desvendados nos estranhos percursos por aquelas ruas transversais. E elas são muitas. Entrar-lhes é despertar temores, o menino poderia perder-se, elas são tantas e tão escuras. Há nelas inúmeras lendas e legendas expostas em cada uma de suas esquinas, em cada gesto de suas prostitutas, malandros e menores engraxates que as atravessam 


\begin{tabular}{|l|l|l|l|l|l|l|}
\hline InterteXto & Uberaba & UFTM & $\begin{array}{l}\text { v. 1 } \\
\text { n. } 2\end{array}$ & p. 82-95 & 2008 - jul. / dez. & ISSN 1981-0601 \\
\hline
\end{tabular}

continuamente pela noite, desarticulando o discurso crível erigido sobre a cidade de São Paulo e abrigando outros imaginários.

\section{As ruas ainda alagadas desde aquele dia: a lembrança}

Pensemos agora numa outra forma de apreender a cidade: por meio das memórias de quem a atravessa, sejam elas remotas ou recentes, traumáticas ou hilárias. Para tanto, observemos o conto "Além do ponto", de Caio Fernando Abreu. Um dos principais narradores dos anos 1980 no Brasil, Caio articulou um delicado exercício entre a experiência de vida do autor e a escrita de ficção. Em sua contística estão presentes, entre outras temáticas, o medo e o horror de inúmeros brasileiros sufocados pelas atrocidades da ditadura militar, a áspera angústia da sobrevivência nos grandes centros urbanos, a solidão e o desterro de quem é estrangeiro dentro de si.

Aliás, esse percurso da falta, busca incessante de um outro espaço e de uma outra pessoa, é o que perpassa "Além do ponto". Nele, um narrador não identificado percorre apressadamente as ruas e avenidas de uma cidade, sob intensa chuva, à noite. Atravessando poças e lama, desviando-se de carros e ônibus, tentando proteger o maço de cigarros e a garrafa de conhaque, ele precisa encontrar, em algum lugar desta cidade, um ponto, uma referência nítida onde haja uma porta, aquela que ele gostaria de abrir. Ou que se the abrisse. Mas a cidade é imensa, a chuva é insuportável, a escuridão o toma por completo, impedindo-o de encontrar aquele ponto, e este se torna, então, indefinido, impreciso e opaco:

Eu precisava deter a vontade de voltar atrás ou ficar parado, pois tem um ponto, eu descobria, em que você perde o comando das próprias pernas, não é bem assim, descoberta tortuosa que o frio e a chuva não me deixavam mastigar direito, eu apenas começava a saber que tem um ponto, e eu dividido querendo ver o depois do ponto, (...), eu ia além daquele ponto de estar parado, agora pelo caminho de árvores sem folhas e a rua interrompida que eu revia daquele jeito estranho de já ter 


\begin{tabular}{|l|l|l|l|l|l|l|}
\hline InterteXto & Uberaba & UFTM & $\begin{array}{l}\text { v. 1 } \\
\text { n. } 2\end{array}$ & p. 82-95 & 2008 - jul. / dez. & ISSN 1981-0601 \\
\hline
\end{tabular}

estado lá sem nunca ter, hesitava mas ia indo, no meio da cidade (...) (ABREU, 2005, p. 46-47).

A narração ocorre em um tempo posterior ao do fato narrado, como observamos pelo uso do pretérito imperfeito: "Eu precisava deter a vontade de voltar atrás ou ficar parado (...)" (Idem, 2005, p. 46). Ou ainda no início do conto: "Chovia, chovia, chovia e eu ia indo por dentro da chuva ao encontro dele, sem guarda-chuva nem nada, eu sempre perdia todos pelos bares, só levava uma garrafa de conhaque barato apertada contra o peito" (Idem, 2005, p. 45). Essa é, então, uma narrativa do que já ocorreu, é um esforço de recordação, um acesso à memória da travessia de uma cidade. Memória, neste conto de Caio, diluída. Relato disperso de impressões mínimas e dúbias. A memória em "Além do ponto", não é localizável já que o relato está em um "além" não definido. Os lugares pelos quais o narrador andou são como presenças de ausências, o que se mostra designa o que não é mais, é um saber que se cala.

Recordação na qual somente circulam meias-palavras. Para imaginar a cidade apresentada por este narrador é preciso aceitá-las. Essa cidade lembrada é uma cidade de ausências: não há como se proteger da chuva e do frio, não há guarda-chuvas, não há dinheiro para o táxi, não há folhas nas árvores, não há ninguém para abrir aquela porta, "Voltar para um lugar quente e seco, se houvesse" (Idem, 2005, p. 46). Também não é mais possível lembrar como retornar: "Parado naquela porta, depois do ponto, tão escuro agora que eu não conseguiria nunca mais encontrar o caminho de volta" (Idem, 2005, p. 48). Cidade de lacunas: "Eu não sabia. Dei alguns passos, como se faz isso, de colocar um pé após outro?, desaprendia, mas como se faz?" (Idem, 2005, p. 47). Cidade brutal: a lembrança da chuva contínua, dos carros hostis, a escuridão, as poças de lama, "Talvez eu tivesse febre, tudo muito confuso" (Idem, 2005, p. 48).

Da mesma forma, é uma cidade recordada por uma incessante busca do outro. Como um animal voraz que caça à noite. No lugar da presa, a porta: "No 


\begin{tabular}{|l|l|l|l|l|l|l|}
\hline InterteXto & Uberaba & UFTM & $\begin{array}{l}\text { v. 1 } \\
\text { n. } 2\end{array}$ & p. 82-95 & 2008 - jul. / dez. & ISSN 1981-0601 \\
\hline
\end{tabular}

meio da cidade como um invisível fio que saindo da cabeça dele até a minha" (Idem, 2005, p. 47). Busca, entretanto, inútil pois ultrapassa todos os incontáveis pontos de referência espalhados pelas ruas alagadas daquela cidade. Memória na qual restam apenas esquinas escuras, "Parar para sempre naquela esquina" (Idem, 2005, p. 46), o que nos mostra uma cidade de inúmeras direções, há vários lugares para ir, mas onde está aquele ponto quando somente há esquinas?

Talvez seja impossível localizar aquela porta. Narrativa de uma memória em fragmento, o conto de Abreu constrói imagens de um espaço resgatado pelo discurso da lembrança. Impreciso e vago, esse discurso percorre as ruas de uma cidade cuja existência forja-se em um "ter passado ali" ou um "talvez ter atravessado aquela avenida", impressões dúbias sobre a forma da cidade mas, no entanto, tão necessárias para sua arquitetura e concepção quanto as diversas outras representações dela estabelecidas.

Seja pela negação dos espaços de habitabilidade do urbano impostos pela administração da cidade ou pelas lembranças dispersas de uma cidade que mais parece um ter sido distante e quase não localizável na memória, é preciso reeducarmos o olhar sobre as cidades. Ou ainda, mudarmos a perspectiva com que a olhamos. As poéticas do crível e do memorável são possibilidades para captar outras representações dos espaços urbanos e das práticas neles realizadas para além das construções aparentemente visíveis da cidade. A literatura, com suas tramas ocultas, personagens imprevisíveis e temporalidades outras, descentraliza esse primeiro olhar e permite o acesso a realidades e imaginários bastante significativos, como percebemos nos contos de João Antônio e Caio Fernando Abreu.

Da mesma forma, o seguinte trecho de uma crônica de Machado de Assis insinua a posição aqui sustentada: "Eu gosto de catar o mínimo e o escondido. Onde ninguém mete o nariz, aí entra o meu, com a curiosidade estreita e aguda que descobre o encoberto. A vantagem dos míopes é enxergar onde as grandes vistas não pegam" (MACHADO DE ASSIS, 1997, p. 


\begin{tabular}{|l|l|l|l|l|l|l|}
\hline InterteXto & Uberaba & UFTM & $\begin{array}{l}\text { v. 1 } \\
\text { n. } 2\end{array}$ & p. 82-95 & 2008 - jul. / dez. & ISSN 1981-0601 \\
\hline
\end{tabular}

145). Enfim, esses lugares "onde as grandes vistas não pegam", neste artigo compreendidos como os discursos do crível e do memorável, são uma metaforização do social obtida, em literatura, por meio do cruzamento de imagens contraditórias ou inesperadas. Se pensarmos com Walter Benjamin (2006) quanto ao seu conceito de contraste é possível enxergar outras formas e práticas espaciais, aqui trazidas pelo conto brasileiro contemporâneo, por contrastes entre as multiplicidades do "concreto" e do "imaginado" urbanos, isto é, criar contra-imagens que rompam com o contínuo da história e com uma inteligibilidade pronta para que possamos obter outras revelações, mínimas, singulares, plurais, sobre as representações e as práticas realizadas na cidade.

\section{Referências}

ANTÔNIO, JOÃO. Malagueta, perus e bacanaço. São Paulo: Cosac Naify, 2004.

ABREU, Caio Fernando. Morangos mofados. Rio de Janeiro: Agir, 2005.

BENJAMIN, Walter. As passagens. Belo Horizonte: Editora da UFMG, 2006.

CALVINO, Ítalo. As cidades invisíveis. São Paulo: Companhia das Letras, 1990.

CERTEAU, Michel de. A invenção do cotidiano. Artes de fazer. Petrópolis: Vozes, 1994.

CHARTIER, Roger. A história cultural entre práticas e representações. Rio de Janeiro: Bertrand Brasil, 1990.

LOTMAN, luri. A estrutura do texto artístico. Lisboa: Editorial Estampa, 1978.

MACHADO DE ASSIS, Joaquim Maria. Obra completa. Rio de Janeiro: Nova Aguilar, 1997.

MONS, Alan. La métaphore social. Paris: PUF, 1992. In: PESAVENTO, Sandra Jatahy. O imaginário da cidade: visões literárias do urbano. Porto Alegre: Editora da UFRGS, 2002.

PESAVENTO, Sandra Jatahy. O imaginário da cidade: visões literárias do urbano. Porto Alegre: Editora da UFRGS, 2002. 


\begin{tabular}{|l|l|l|l|l|l|l|}
\hline InterteXto & Uberaba & UFTM & $\begin{array}{l}\text { v. 1 } \\
\text { n. } 2\end{array}$ & p. 82-95 & 2008 - jul. / dez. & ISSN 1981-0601 \\
\hline
\end{tabular}

SÜSSEKIND, Flora. Desterritorialização e forma literária: literatura brasileira contemporânea e forma urbana. In: Revista Literatura e Sociedade. São Paulo: USP/ FFLCH/DTTLLC, n 8, p. 60-81, 2005. 